\title{
LATERALIZATION OF EPILEPTIFORM DISCHARGES IN PATIENTS WITH EPILEPSY AND PRECOCIOUS DESTRUCTIVE BRAIN INSULTS
}

\author{
Ricardo A. Teixeira', Li M. Li', Sergio L.M. Santos², \\ Bárbara J. Amorim², Elba C.S.C. Etchebehere², \\ Verônica A. Zanardi², Carlos A.M. Guerreiro', Fernando Cendes ${ }^{1}$
}

\begin{abstract}
Unilateral destructive brain lesions of early development can result in compensatory thickening of the ipsilateral cranial vault. The aim of this study was to determine the frequency of these bone changes among patients with epilepsy and precocious destructive lesions, and whether a relationship exists between these changes and epileptiform discharges lateralization. Fifty-one patients had their ictal / interictal scalp EEG and skull thickness symmetry on MRI analyzed. Patients were divided into three main groups according to the topographic distribution of the lesion on the MRI: hemispheric $(H)(n=9)$; main arterial territory $(A T)(n=25)$; arterial borderzone $(B d z)(n=17)$. The EEG background activity was abnormal in 26 patients and were more frequent among patients of group $H(p=0.044)$. Thickening of the skull was more frequent among patients of group $H(p=0.004)$. Five patients $(9.8 \%)$ showed discordant lateralization between epileptiform discharges and structural lesion (four of them with an abnormal background, and only two of them with skull changes). In one of these patients, ictal SPECT provided strong evidence for scalp EEG false lateralization. The findings suggest that compensatory skull thickening in patients with precocious destructive brain insults are more frequent among patients with unilateral and large lesions. However, EEG lateralization discordance among these patients seems to be more related to EEG background abnormalities and extent of cerebral damage than to skull changes.
\end{abstract}

KEY WORDS: hemiatrophy, infarct, MRI, EEG, Dyke-Davidoff-Masson syndrome.

\section{Lateralização de descargas epileptiformes em pacientes com epilepsia e lesões cerebrais destru- tivas precoces}

RESUMO - Lesões cerebrais destrutivas unilaterais ocorridas em fase precoce do desenvolvimento podem resultar em espessamento compensatório da calota craniana ipsilateral. O objetivo deste estudo foi determinar a freqüência destas alterações ósseas em pacientes com epilepsia e lesões destrutivas precoces e avaliar se há associação entre estas alterações e lateralização de descargas epileptiformes. Foram analisados EEGs interictais / ictais e espessura do crânio pela RM de 51 pacientes. Os pacientes foram divididos em três grupos de acordo com a distribuição topográfica da lesão à RM: hemisférico $(H)(n=9)$; território arterial $(A T)$ $(n=25)$; fronteira arterial $(B d z)(n=17)$. A atividade de base no EEG foi anormal em 26 pacientes e foi mais freqüente entre os pacientes do grupo $H(p=0,044)$. Espessamento unilateral da calota craniana foi mais freqüente entre os pacientes do grupo $H(p=0,004)$. Cinco pacientes $(9,8 \%)$ apresentaram discordância lateralizatória entre as descargas epileptiformes e lesão estrutural (quatro deles com atividade de base anormal, e apenas dois deles com espessamento da calota craniana). Em um destes pacientes, o SPECT ictal revelou forte evidência de falsa lateralização pelo EEG. Os achados sugerem que o espessamento compensatório da calota craniana é mais freqüente entre pacientes com lesões unilaterais e extensas. No entanto, a lateralização de descargas epileptiformes parece estar mais relacionada ao grau de alteração da atividade de base e extensão da lesão cerebral do que às alterações ósseas.

PALAVRAS-CHAVE: hemiatrofia, infarto, RM, EEG, Dyke-Davidoff-Masson syndrome.

In their original work, Dyke, Davidoff and Masson ${ }^{1}$ described the radiological changes occurring in the skull of nine patients with the clinical diagno- sis of "infantile hemiplegia": thickening of the cranial vault on the same side of the cerebral lesion, overdevelopment of the frontal and ethmoid sinus-

Departments of Neurology ${ }^{1}$ and Radiology ${ }^{2}$, State University of Campinas (UNICAMP), Campinas SP, Brazil. Dr. Ricardo A. Teixeira was supported by a grant from Fundação de Amparo à Pesquisa do Estado de São Paulo (FAPESP), \# 98/13101-8.

Received 27 June 2003. Accepted 16 September 2003.

Dr. Fernando Cendes - Department of Neurology, FCM-UNICAMP - Caixa Postal 6111 - 13083-970 Campinas SP - Brasil. E-mail: fcendes@unicamp.br 
es and of the air cells of the petrous pyramid of the temporal bone. These compensatory bone changes are the result of precocious unilateral loss of cerebral volume, due to a variety of congenital and acquired pathological processes. The clinical presentation consists of variable degrees of hemiplegia, hemiatrophy, mental retardation and seizures. The combination of those clinical and imaging features became known as the Dyke-DavidoffMasson syndrome ${ }^{2,3}$. Sammaritano et al. ${ }^{2}$ emphasized the importance of a critical interpretation of the surface EEG in patients with epilepsy and large unilateral cerebral lesions. Patients with large hemispheric lesions can present bilateral synchronous or independent interictal epileptic discharges that in some instances "predominate" in the hemisphere contralateral to the lesion. The EEG background activity of the intact hemisphere will be higher in amplitude and can overshadow the low voltage activity of the lesioned hemisphere, leading to a false lateralization.

Besides the large extension of the lesion, thickening of the adjacent skull could also contribute to the false lateralization described by Sammaritano et al. ${ }^{2}$ in patients with destructive lesions of early development. However, as far as we know, no study has investigated the significance of these skull abnormalities in lateralization of epileptic discharges. There is evidence that magnetic resonance imaging (MRI) can demonstrate the compensatory bone changes in Dyke-Davidoff-Masson syndrome as easily as computed tomography (CT) and can afford additional details of brain lesion that CT can not ${ }^{2-4}$.

This study was designed to access the lateralization of epileptogenic discharges and the frequency of compensatory skull changes in patients with different patterns of precocious destructive lesions. We also tested the hypothesis that lateralization of epileptogenic discharges varies according to the presence of skull thickening.

\section{METHOD}

We studied 51 consecutive adult patients ( 22 women) seen at the Epilepsy Clinic of UNICAMP from March 1999 to April 2001 with the diagnosis of epilepsy secondary to a destructive brain lesion of early development (mean age $=31.8$ years; range $=15-55$ years). Informed consent was obtained from all subjects. This study was approved by the Ethics Committee of the Faculty of Medical Sciences of UNICAMP. Further details about clinical and MRI findings about these patients were described in a recent publication ${ }^{5}$.
Detailed histories of prenatal, neonatal and early childhood events were systematically reviewed through the medical records and direct interview with the parents. All patients had disease onset before the fifth year of age. We excluded patients with foreign tissue lesions detected on MRI as well as those with history of major traumatic brain injury or with signs of progressive disease.

Previous electroencephalographic data were reviewed and all patients had serial routine EEG studies using the 10-20 system with additional anterior temporal and zygomatic electrodes. Eleven patients had long-term video-EEG monitoring with scalp electrodes for recording of their habitual seizures.

MRI was performed in a 2.0 T scanner (Elscint Prestige, Haifa, Israel). Our epilepsy protocol consists of: a) sagital T1 spin-echo, $6 \mathrm{~mm}$ thick (TR=430, TE= 12) for optimal orientation of the subsequent images; $b$ ) coronal T1 inversion recovery (IR), $3 \mathrm{~mm}$ thick (flip angle $=200^{\circ} ; \mathrm{TR}=2700$, $\mathrm{TE}=14, \mathrm{TI}=840$, matrix $=130 \times 256$, FOV $=16 \times 18 \mathrm{~cm}$ ); c) coronal T2-weighted "fast spin-echo" (FSE), 3-4mm thick (flip angle $=120^{\circ}, \mathrm{TR}=4800, \mathrm{TE}=129$, matrix $=252 \times 320$, FOV $=18 \times 18 \mathrm{~cm}$ ); d) axial images parallel to the long axis of the hippocampus; T1 gradient echo (GRE), 3mm thick (flip angle $=70^{\circ}, \mathrm{TR}=200, \mathrm{TE}=5$, matrix $=180 \times 232$, FOV $=22 \times 22 \mathrm{~cm}$ ); e) axial T2 FSE, $4 \mathrm{~mm}$ thick (flip angle $=120^{\circ}$, $\mathrm{TR}=6800, \mathrm{TE}=129$, matrix $=252 \times 328, \mathrm{FOV}=21 \times 23 \mathrm{~cm}$ ); f) volumetric (3D) T1 GRE, acquired in the sagital plane for multiplanar reconstruction, 1-1.5mm thick (flip angle $=35^{\circ}, \mathrm{TR}=22, \mathrm{TE}=9$, matrix $=256 \times 220, \mathrm{FOV}=23 \times 25 \mathrm{~cm}$ ).

Visual analysis of MRI and multiplanar reconstruction were systematically performed in a workstation $\left(\mathrm{O}_{2}\right.$ Silicon Graphic) using Omnipro software (Elscint Prestige, Haifa, Israel). Qualitative analysis of the skull thickness symmetry was made by one of us (SLMS) who was blinded to the clinical and EEG data. Patients were divided in three different groups according to the topographical distribution of the lesion: Hemispheric lesions $(H)$; patients in this group had an homogeneous atrophy of an entire hemisphere without loss of tissue continuity. Arterial territory lesions $(A T)$; this group had their lesions limited to a main arterial territory, constituted by a cavitation or a localized retraction of the cerebral tissue with an heterogeneous appearance suggestive of a substantial gliotic scar. Arterial borderzone lesions ( $B d z)$; these patients had their lesions consisting of atrophy between the main cerebral arterial territories with an ulegyric aspect ${ }^{6,7}$. Eleven patients showed more than one of these lesional patterns and they were classified according to the most exuberant pattern.

One patient was also submitted to brain SPECT images. She was injected with $1110 \mathrm{MBq}$ of $99 \mathrm{mTC}-\mathrm{ECD}$ while resting in a dark, quiet room (inter-ictal brain SPECT) and 4 seconds after clinical onset of one of her habitual seizures (ictal brain SPECT). The images were acquired in a scintillation camera-computer system equipped with 
a fan-beam collimator. Sixty images were acquired, at 60 intervals for a total of 360o. Images were normalized, a Metz filter and attenuation correction were applied. The images were reconstructed in the transaxial, coronal, and sagittal planes.

We used the Pearson's chi-square $\left(\chi^{2}\right)$ or Fisher's exact test for comparing proportions among groups. We considered the significance level of 0.05 .

\section{RESULTS}

Fifty-one patients were distributed in the three different groups as follows: $H(n=9), A T(n=25), B d z$ $(n=17)$. The EEG and MR findings are summarized in Table 1.

\section{EEG analysis}

The background activity was abnormal in 26 patients $(51 \%)$ including voltage asymmetry $(n=15)$, continuous slowing over one hemisphere $(n=9)$ and diffuse slowing $(n=3)$. These abnormalities were more frequent among patients of group $H(77,7 \%)$ than groups $B d z(29.4 \%)$ and $A T(56 \%)(\chi 2$ [2]=6.257, $p=0.044$ ).

Epileptiform activity was present in routine EEGs of 38 patients $(74.5 \%)$; in 33 of them it was lateralized and concordant with the lesion, in one it was not lateralized, and in four it was consistently discordant. Three out of these four patients (Patients 3, 6 and 49) presented an abnormal background activity with voltage reduction ipsilateral to the lesion and contralateral to the epileptiform activity. In patients from $B d z$ group who had bilateral lesions, EEG was considered concordant when it was ipsilateral to the most robust lesion.

Ictal surface EEG was recorded in eleven patients. In seven patients (Patients 24, 27, 33, 44, 46, 48 and 51) ictal onset was ipsilateral to the lesion. Two patients had nonlocalizing ictal EEG (Patients 32 and 42). We observed in further two patients (Patients 3 and 39) a bitemporal seizure onset with electrical activity of higher voltage over the hemisphere contralateral to the lesion. Both presented an abnormal background activity with voltage reduction ipsilateral to the lesion.

\section{MRI analysis}

Bone thickening of the skull adjacent to the lesion was observed more frequently among patients of group $H(7 / 9)$ than groups $A T(11 / 25)$ and $B d z$ $(2 / 17)(\chi 2[2]=11.29, \mathrm{p}=0.004)$.

Patients from group $H$ constituted a continuum of hemiatrophy severity. The two patients who presented a symmetric skull thickness could be ca- tegorized as the less severe pole of this spectrum of hemiatrophy (Fig 1).

Among patients from group $B d z$, fourteen (82\%) exhibited bilateral lesions. Twelve $(70 \%)$ had the lesion distributed posteriorly on the watershed between the three main arteries. Five patients had their lesions more anteriorly, on the watershed between the anterior cerebral artery (ACA) and middle cerebral artery (MCA). The two patients who exhibited skull thickening (Patients 25 and 26) were those who had the more extensive lesions from the group, one of them associated to a clastic lesion on the territory of the MCA (Patient 26).

Nineteen patients from group $A T(76 \%)$ presented lesions on the territory of the MCA, four on the posterior cerebral artery (PCA) and two on the ACA. Among patients with MCA lesions, those with lesions of the whole territory had skull thickening more frequently (7/9) than those with lesions over MCA divisions (4/10), but this difference did not reach significance $(\chi 2[1]=2.77, p=0.096)$. Patients with lesions on PCA and ACA did not show skull thickening. There was no difference in frequency of skull thickening between patients with cystic (5/14) and atrophic lesions (6/11) $(\chi 2[1]=0.89$, $p=0.346)$. However, we could observe that there were no skull changes among patients with large cystic lesions communicating to the lateral ventricle and extending up to the convexity as a single cavity (porencephaly) (Patients 35,36,38,40,48 and 49). Conversely, patients with multicystic encephalomalacia had intact ventricular walls (Patients 34, $39,41,43,44$ and 45$)$, and all showed skull thickening (Fig 2).

\section{Patients with EEG and MRI discordance}

Five patients out of 51 (9.8\%) showed discordant lateralization between epileptiform discharges and structural lesion.

Patient 3. A 39-year-old woman had normal development until her second year of life when she had an episode of status epilepticus without any apparent precipitating event, followed by a permanent left hemiparesis. By the age of seven she started to present habitual seizures characterized by partial complex seizures preceded by a throat discomfort, which remained without control even after multiple drug regimens. Interictal EEG showed right hemisphere voltage reduction and sharp waves exclusively over the left temporal region in successive EEGs. Video-EEG recorded three complex partial seizures, two of them associated with a left 
Table 1. EEG and MRI features

\begin{tabular}{|c|c|c|c|c|c|}
\hline $\begin{array}{l}\mathrm{Pt} / \mathrm{Sex} / \\
\text { Age(y) }\end{array}$ & Group & $\begin{array}{l}\text { Lesion distribution } \\
\text { on MRI }\end{array}$ & $\begin{array}{l}\text { Skull adjacent } \\
\text { to the lesion }\end{array}$ & Interictal EEG & Ictal EEG \\
\hline $1 / \mathrm{M} / 41$ & $\mathrm{H}$ & L Hem + R Bdz (ACA-MCA) & $\mathrm{nl}$ & $\mathrm{nl}$ & NA \\
\hline 2/F/39 & $\mathrm{H}$ & R Hem & thick & BiT > R, diffuse slowing & NA \\
\hline 3/F/45 & $\mathrm{H}$ & R Hem & thick & $\mathrm{L} T, \downarrow$ voltage $\mathrm{R} \mathrm{Hem}$ & $\mathrm{BiT}>\mathrm{L}$ \\
\hline $4 / \mathrm{M} / 17$ & $\mathrm{H}$ & R Hem & $\mathrm{nl}$ & $\mathrm{RT}$ & NA \\
\hline $5 / F / 44$ & $\mathrm{H}$ & R Hem & thick & $\begin{array}{l}\mathrm{R} \text { post quadrant, } \\
\downarrow \text { voltage } \mathrm{R} \mathrm{Hem}\end{array}$ & NA \\
\hline $6 / \mathrm{M} / 40$ & $\mathrm{H}$ & R Hem & thick & $\mathrm{LFT}, \downarrow$ voltage $\mathrm{R}$ Hem & NA \\
\hline $7 / F / 48$ & $\mathrm{H}$ & R Hem + L Bdz (ACA-MCA) & thick & $\downarrow$ voltage $\mathrm{R}$ Hem & NA \\
\hline $8 / M / 37$ & $\mathrm{H}$ & $\begin{array}{l}\text { R Hem + bilateral } \\
\text { Bdz (ACA-MCA-PCA) }\end{array}$ & thick & R T, R Hem slowing & NA \\
\hline 9/F/34 & $\mathrm{H}$ & $\mathrm{R}$ hem & thick & BiT > R, R Hem slowing & NA \\
\hline 10/M/17 & $\mathrm{Bdz}$ & bilateral (ACA-MCA-PCA) & $\mathrm{nl}$ & $\mathrm{R}$ post quadrant & NA \\
\hline $11 / \mathrm{M} / 19$ & $\mathrm{Bdz}$ & bilateral > L (ACA-MCA) & $\mathrm{nl}$ & $\mathrm{BiT}>\mathrm{L}$ & NA \\
\hline $12 / F / 31$ & $\mathrm{Bdz}$ & bilateral > R (ACA-MCA) & $\mathrm{nl}$ & R T & NA \\
\hline $13 / \mathrm{M} / 51$ & $\mathrm{Bdz}$ & R MCA-PCA & $\mathrm{nl}$ & $\mathrm{BiT}>\mathrm{R}$ & NA \\
\hline $14 / \mathrm{M} / 21$ & $\mathrm{Bdz}$ & $\begin{array}{l}\text { bilateral (ACA-MCA-PCA) } \\
+ \text { L trigone leucomalacia }\end{array}$ & $\mathrm{nl}$ & R T & NA \\
\hline 15/M/53 & $\mathrm{Bdz}$ & bilateral > L (ACA-MCA) & $\mathrm{nl}$ & LT & NA \\
\hline $16 / \mathrm{M} / 21$ & $\mathrm{Bdz}$ & bilateral (ACA-MCA-PCA) & $\mathrm{nl}$ & diffuse slowing & NA \\
\hline 17/F/39 & $\mathrm{Bdz}$ & bilateral (ACA-MCA) & $\mathrm{nl}$ & LT & NA \\
\hline $18 / F / 27$ & $\mathrm{Bdz}$ & bilateral > L (ACA-MCA-PCA) & $\mathrm{nl}$ & R FT & NA \\
\hline 19/F/36 & $\mathrm{Bdz}$ & bilateral > L (ACA-MCA-PCA) & $\mathrm{nl}$ & L TO & NA \\
\hline $20 / \mathrm{M} / 36$ & $\mathrm{Bdz}$ & bilateral (ACA-MCA-PCA) & $\mathrm{nl}$ & L post quadrant slowing & NA \\
\hline $21 / F / 38$ & $\mathrm{Bdz}$ & L ACA-MCA & $\mathrm{nl}$ & $L T$ & $\mathrm{~N}$ \\
\hline $22 / F / 55$ & $\mathrm{Bdz}$ & bilateral (ACA-MCA-PCA) & $\mathrm{nl}$ & $\mathrm{nl}$ & NA \\
\hline $23 / \mathrm{M} / 20$ & $\mathrm{Bdz}$ & $\begin{array}{l}\text { bilateral (ACA-MCA-PCA) + } \\
\text { L MCA clastic lesion }\end{array}$ & $\mathrm{nl}$ & $\mathrm{nl}$ & NA \\
\hline $24 / F / 23$ & $\mathrm{Bdz}$ & bilateral > L (ACA-MCA-PCA) & $\mathrm{nl}$ & $\begin{array}{l}\mathrm{LT}, \downarrow \text { voltage } \mathrm{L} \\
\text { post quadrant }\end{array}$ & L T \\
\hline $25 / F / 38$ & $\mathrm{Bdz}$ & $\begin{array}{l}\text { bilateral }>L(\text { ACA-MCA-PCA })+ \\
L \text { MCA clastic lesion }\end{array}$ & thick & $\begin{array}{l}\mathrm{LT}, \downarrow \text { voltage } \mathrm{L} \\
\text { post quadrant }\end{array}$ & NA \\
\hline $26 / F / 40$ & $\mathrm{Bdz}$ & bilateral > R (ACA-MCA-PCA) & thick & $\begin{array}{l}\text { BiT }>R, \downarrow \text { voltage } R \\
\text { post quadrant }\end{array}$ & NA \\
\hline 27/M/39 & AT & R MCA (Atrophy-perisilvian) & $\mathrm{nl}$ & R T & R FT \\
\hline $28 / \mathrm{M} / 26$ & AT & R MCA (Atrophy-perisilvian) & $\mathrm{nl}$ & R Hem slowing & NA \\
\hline 29/M/28 & AT & L MCA (Atrophy-perisilvian) & $\mathrm{nl}$ & $\mathrm{nl}$ & NA \\
\hline 30/M/34 & AT & L MCA (Atrophy-perisilvian) & thick & LFT & NA \\
\hline $31 / \mathrm{M} / 44$ & AT & R MCA (Atrophy-perisilvian) & $\mathrm{nl}$ & $\mathrm{BiT}>\mathrm{E}$ & NA \\
\hline $32 / \mathrm{M} / 20$ & AT & L MCA) (Atrophy - perisilvian) & thick & L T, L Hem slowing & nonlocalizing \\
\hline 33/F/22 & AT & L MCA (Atrophy -perisilvian) & thick & L T, L Hem slowing & LT \\
\hline $34 / F / 27$ & AT & L temporo-occipital (ME) & thick & $\mathrm{nl}$ & NA \\
\hline $35 / \mathrm{M} / 36$ & AT & L parietal (Por) & $\mathrm{nl}$ & $\mathrm{nl}$ & NA \\
\hline $36 / \mathrm{M} / 33$ & AT & R parietal (Por) & $\mathrm{nl}$ & $\mathrm{nl}$ & NA \\
\hline $37 / M / 25$ & AT & $\begin{array}{l}\text { R MCA (ME -whole territory) + } \\
\text { L Bdz (ACA-MCA) }\end{array}$ & thick & R T, R T slowing & NA \\
\hline $38 / \mathrm{M} / 37$ & AT & $\begin{array}{l}\text { L MCA (Por - whole territory) + } \\
\text { R Bdz (ACA-MCA) }\end{array}$ & $\mathrm{nl}$ & $\mathrm{L} T, \downarrow$ voltage $\mathrm{L} \mathrm{Hem}$ & NA \\
\hline $39 / F / 26$ & AT & L MCA (ME - whole territory) & thick & $\begin{array}{l}\mathrm{LT}, \downarrow \text { voltage } \mathrm{L} \\
\text { post quadrant }\end{array}$ & $\mathrm{BiT}>\mathrm{R}$ \\
\hline $40 / F / 50$ & AT & $\begin{array}{l}\text { L MCA } \\
\text { (Por - whole territory) }\end{array}$ & $\mathrm{nl}$ & $\mathrm{L} \mathrm{T}, \downarrow$ voltage $\mathrm{L} \mathrm{Hem}$ & NA \\
\hline $41 / \mathrm{M} / 15$ & AT & $\begin{array}{l}\text { R MCA (ME - whole territory) + } \\
\text { bilateral Bdz (ACA-MCA-PCA) }\end{array}$ & thick & $\begin{array}{l}\mathrm{R} \text { multifocal, } \downarrow \\
\text { voltage } \mathrm{R} \text { Hem }\end{array}$ & NA \\
\hline $42 / \mathrm{M} / 36$ & AT & $\begin{array}{l}\text { R MCA (Atrophy -whole } \\
\text { territory) + central bilateral }\end{array}$ & thick & BiF $>R$, diffuse slowing & nonlocalizing \\
\hline $43 / \mathrm{M} / 28$ & AT & L MCA (ME - whole territory) & thick & $\begin{array}{l}\text { diffuse slowing, } \downarrow \\
\text { voltage L Hem }\end{array}$ & NA \\
\hline $44 / \mathrm{M} / 27$ & AT & R MCA (ME - whole territory) & thick & $\begin{array}{l}\mathrm{R} \mathrm{T}, \downarrow \text { voltage /slowing } \mathrm{R} \\
\text { post quadrant }\end{array}$ & $\mathrm{RT}$ \\
\hline $45 / F / 18$ & AT & L MCA (ME - whole territory) & thick & L TP & NA \\
\hline $46 / \mathrm{M} / 22$ & AT & L PCA (Atrophy) & $\mathrm{nl}$ & L TO & LO \\
\hline $47 / \mathrm{M} / 18$ & AT & L PCA (Atrophy) & $\mathrm{nl}$ & $\begin{array}{l}\text { L TO, L post quadrant } \\
\text { slowing }\end{array}$ & NA \\
\hline $48 / F / 35$ & AT & L PCA (Por) & $\mathrm{nl}$ & $\begin{array}{l}\mathrm{LT}, \mathrm{L} \text { post quadrant } \\
\text { slowing }\end{array}$ & L T \\
\hline $49 / F / 25$ & AT & R PCA (Por) & $\mathrm{nl}$ & $\begin{array}{l}\text { BiT }>\mathrm{L}, \downarrow \text { voltage } \mathrm{R} \\
\text { post quadrant }\end{array}$ & NA \\
\hline $50 / \mathrm{M} / 22$ & AT & R ACA (Atrophy) & $\mathrm{nl}$ & $\mathrm{nl}$ & NA \\
\hline $51 / F / 20$ & AT & R ACA (Atrophy) & $\mathrm{nl}$ & R FT & R F \\
\hline
\end{tabular}

$L=$ left; $R=$ right; $H=$ hemispheric distribution; $A T=$ arterial territory distribution; $B d z=$ vascular borderzone distribution; $A C A=$ anterior cerebral artery; $M C A=$ mid dle cerebral artery; $P C A=$ posterior cerebral artery; Hem = hemispheric; Por = porencephaly; $M E=$ multicystic encephalomalacia; post = posterior; $F=$ frontal; $T=$ dle cerebral artery; $P C A=$ posterior cerebral artery; Hem 

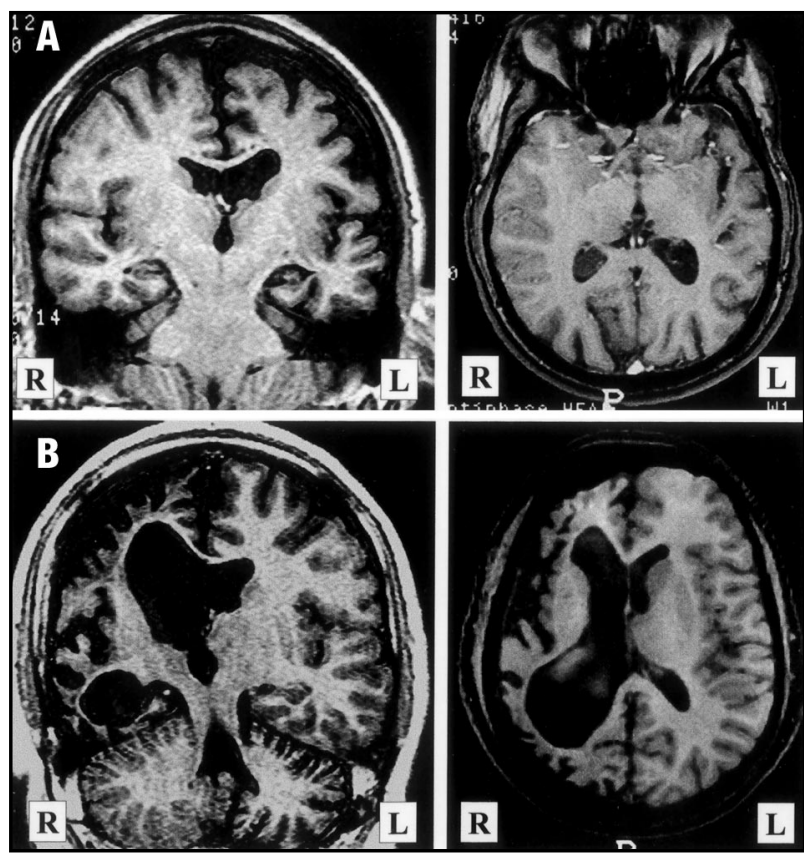

Fig 1. Illustration of different grades of hemiatrophy severity and their relationship to skull changes. A) Patient 1. Slight to moderate left hemiatrophy and no skull changes; B) Patient 7. Severe right hemiatrophy associated to adjacent thickening of the cranial vault.

hand dystonia. The ictal EEG discharges first began to appear approximately 5 seconds after clinical onset, involving both hemispheres but with unequivocal left side amplitude predominance. In one of the seizures, radioligand for SPECT images was injected 4 seconds after clinical onset and one second before EEG discharges. Interestingly, the ictal brain SPECT images showed marked hyperperfusion in the right temporal region (Fig 3). This same region was hypoperfused in the interictal study indicating that this region was the epileptic focus. The MRI showed a right hemiatrophy associated with a marked right hippocampal atrophy with ipsilateral compensatory skull thickening. She was submitted to a right standard anterior temporal lobe removal including amygdala and anterior portion of the hippocampus, and remains seizure free after a period of 12 months.

Patient 6. A 44-year-old man with a previous history of neonatal seizure had normal development until the $6^{\text {th }}$ year of age when he presented an episode of status epilepticus, followed by a permanent left hemiparesis and recurrent seizures. His habitual seizures were partially controlled with antiepileptic drugs (AED) and were of two kinds: sensitive partial seizures involving the left arm and complex partial seizures. Interictal EEG showed
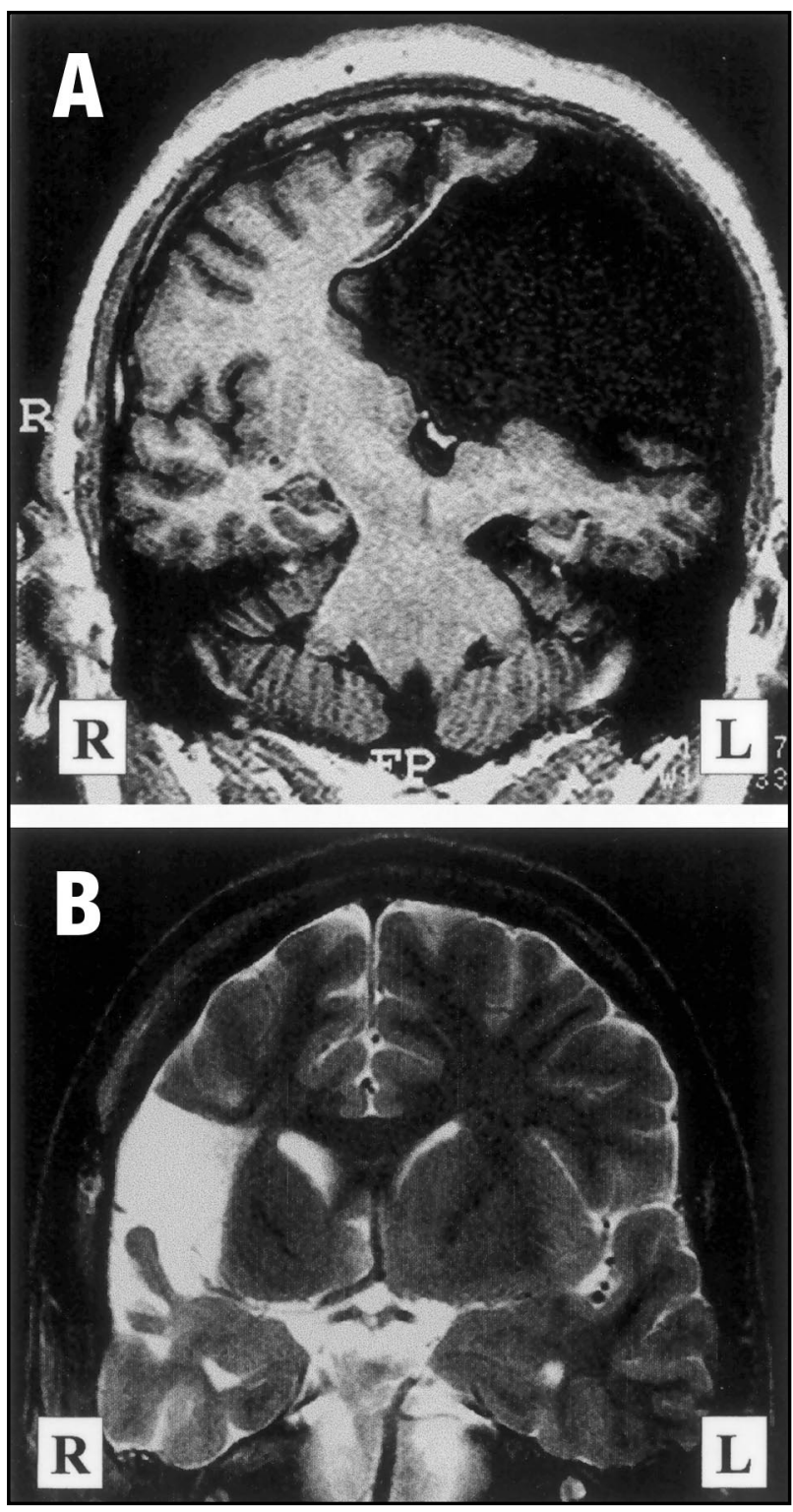

Fig 2. Examples of two kinds of cystic lesions showing different effects over the adjacent skull. A) Patient 38. A 37-year-old man with a congenital right hemiparesis and a left porencephaly over the territory of the middle cerebral artery (MCA). The lesion is in broad communication with the lateral ventricle extending until the convexity and no compensatory bone thickening can be detected; B) Patient 37. A 25-year-old man with a congenital left hemiparesis and a multicystic encephalomalacia over the right MCA. Adjacent compensatory bone thickening can be observed, probably due to impairment of pressure against the convexity exerted by the gliotic "cells". In this way, the equalization of pressure is brought in part by thickening of the skull.

right hemisphere voltage reduction and sharp waves exclusively over the left fronto-temporal region in several exams. On MRI, there was a right hemiatrophy and ipsilateral thickening of the cranial vault. 


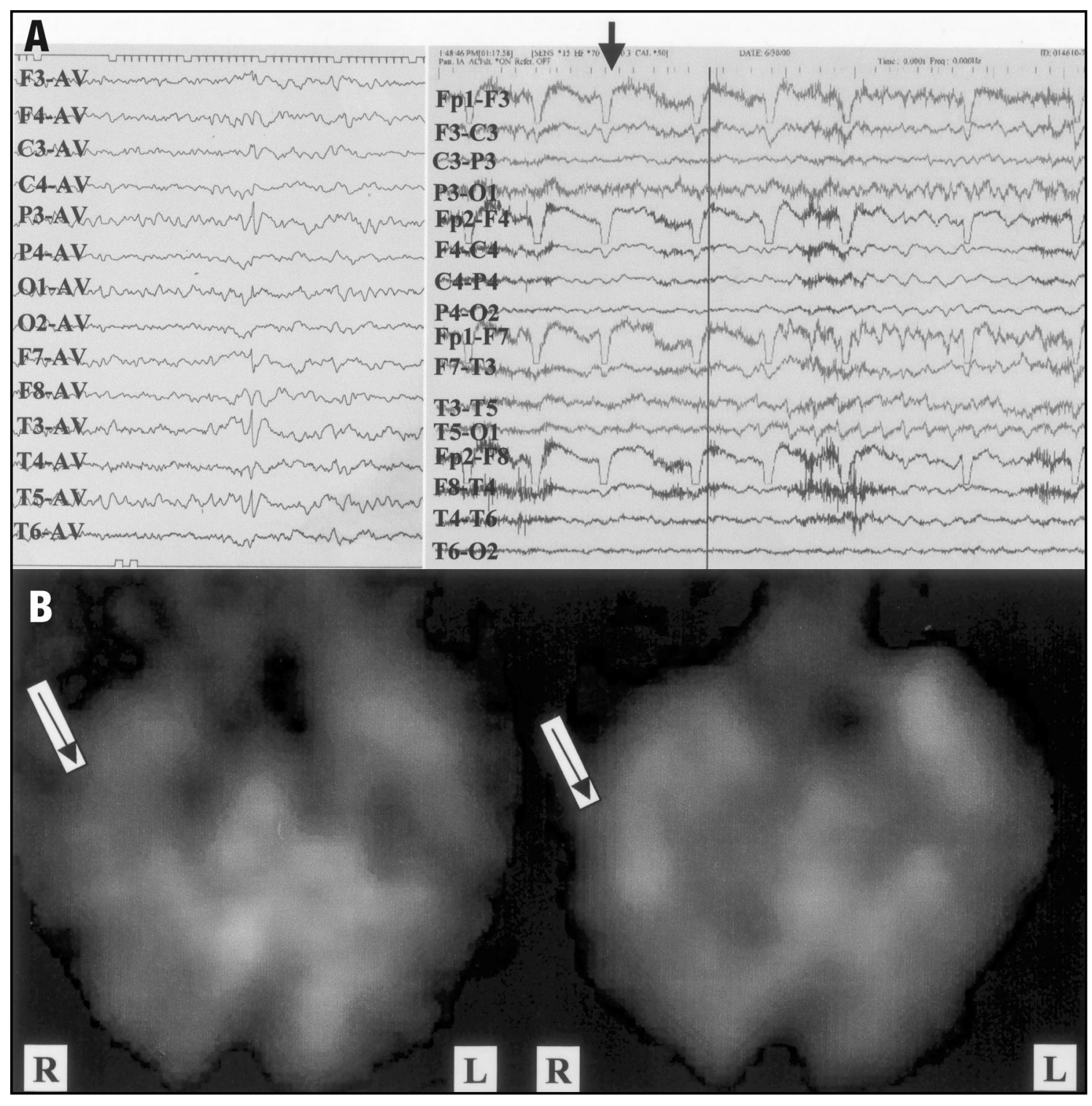

Fig 3. A 39-year-old woman with intractable temporal lobe epilepsy and a right hemiatrophy with adjacent skull thickening. A) Repeated interictal EEGs (left) showed epileptiform discharges restricted to the left temporal lobe and background voltage reduction over the right hemisphere. Ictal scalp EEG (right), although with large amount of artifacts, shows beginning of rhythmic activity apparently in both hemispheres (black bar) but with unequivocal left sided amplitude predominance. B) In order to perform brain SPECT images, 99mTC-ECD was injected 4 seconds after clinical onset and one second before EEG discharges (arrow). Interictal SPECT (left) shows diffuse hypoperfusion of the right hemisphere, mainly in the temporal lobe (white arrow). Ictal SPECT (right) shows unequivocal hyperperfusion in the right temporal lobe (white arrow). This patient was submitted to a right standard anterior temporal lobe removal including amygdala and anterior portion of the hippocampus, and remains seizure free after a period of 12 months.

Patient 31. A 44-year-old man with a discrete right hemiparesis and recurrent seizures since the age of 13 . He had monthly motor partial seizures involving the left hand and occasionally a complex partial seizure. Interictal EEG showed bitemporal epileptic discharges, synchronic or independently, and it was substantially more common on left side. The MRI showed a right perisylvian atrophy and no skull changes.
Patient 39. A 26-year-old woman with a congenital right hemiparesis. Her mother suffered recurrent abdominal traumas during gestation. She presented a first seizure by the age of one year and recurrent seizures when she was nine years old. Her habitual seizures in adult life were weekly complex partial seizures with automatic behavior, despite the use of high doses of AED. Interictal EEGs showed voltage reduction over the left posterior qua- 
drant and remarkable epileptic discharges over the left temporal region. Ictal EEG recordings showed a bitemporal electrographic ictal onset with right side amplitude predominance, in a total of four seizures recorded. The MRI showed a multicystic encephalomalacia over the whole territory of the left MCA with ipsilateral hippocampal atrophy and no skull changes. A left standard anterior temporal lobe removal including amygdala and anterior portion of the hippocampus was performed and the patient remained seizure-free for a period of 26 months and now presents rare seizures (Engel's class II) ${ }^{8}$.

Patient 49. A 25-year-old woman with a normal development until the age of 11 years when she began to present recurrent seizures described as a rising epigastric sensation followed by a complex partial seizure. One seizure was witnessed by one of us, when a dystonic posture of the left hand could be observed. The seizures were refractory to AED and occurred weekly. The MRI revealed a cystic lesion in communication with the lateral ventricle over the territory of the right PCA, an ipsilateral hippocampal atrophy and no skull changes. Interictal EEGs demonstrated reduced voltage over the right posterior quadrant and bitemporal epileptic discharges with predominance of voltage and frequency over the left side. A right standard anterior temporal lobe removal including amygdala and anterior portion of the hippocampus was performed and the patient remains only with rare simple partial seizures (epigastric sensation) after a follow-up of two years and eight months.

\section{DISCUSSION}

We studied a group of epileptic patients with heterogeneous neuropathologic conditions that have in common the finding of precocious brain tissue destruction. We grouped these patients based on the topographical distribution of their lesions on MRI and in this way we created three nearly homogenous groups ${ }^{5}$.The frequency of compensatory skull thickening was greater among patients with hemiatrophy (group $H$ ). This is in agreement with previous studies that show precocious unilateral and large lesions associated to Dyke-DavidoffMasson syndrome ${ }^{1,3,4}$. In fact, the term hemiatrophy is often used in the neurological and radiological literature to describe any large destructive unilateral lesion (e.g, MCA infarct) ${ }^{3,4}$, but the neuropathological literature advocate its use to homogeneous atrophic lesions of the whole hemisphere without loss of tissue continuity ${ }^{9-10}$. Our classification follows this neuropathological perspective. On the opposite end of the spectrum of lesions analyzed in this study, there are borderzone lesions that are usually subtle, bilateral and rarely associated with skull abnormalities.

An interesting finding among patients from group AT was that cystic lesions in communication with the lateral ventricle and extending until the convexity as a single cavity (porencephaly) were not associated with skull changes. Conversely, all patients with multicystic encephalomalacia presented compensatory bone thickening. This suggests that the pressure that these two patterns of cystic lesions exert against the skull is quite different. A multicystic lesion would have a reduced potential for expansion since the gliotic tissue works as "containers", and in this way the equalization of pressure is brought in part by thickening of the skull. This is in agreement with Laplace's law which states that the force exerted by a fluid-filled cavity against its surface is directly proportional to the diameter of the cavity.

In our study, lateralization of epileptiform discharges was discordant to the lesion in nearly $10 \%$ of the patients. In a study of twenty-five children with post-hemiconvulsive hemiplegia, nine (36\%) showed interictal epileptiform discharges exclusively over the non-affected hemisphere ${ }^{11}$. Ito et al. ${ }^{12}$ described two cases with discordance of epileptiform discharges on EEG and CT among 41 children with congenital hemiplegia. A study before the advent of $C T$ in children with congenital hemiplegia evidenced a lateralization discordance between EEG and presumed affected hemisphere in $24 \%$ of patients $^{13}$. The study of Sammaritano et al. ${ }^{2}$ was very elucidative as it could be elegantly demonstrated by invasive EEG recordings that in patients with large destructive lesions, a lateralization discordance between lesion and scalp EEG can be false due to a limitation of the method (extracranial EEG).

In our study, only two out of five patients with lateralization discordance showed skull changes. In contrast, four out of five patients presented EEG background abnormalities. This suggests that changes of EEG background are more relevant than skull changes for this lateralization discordance, but this needs to be confirmed by a larger series.

It is likely that the dorsal hippocampal comissure $\mathrm{e}^{14,15}$ may also have a relevant role in inter- 
hemispheric synchrony among patients with large destructive hemispheric lesions, since the neocortical pathways are extensively damaged. Seizure spread to the contralateral temporal hippocampus and neocortex would occur prior to involvement of adjacent neocortical structures of the ipsilateral hemisphere. However, the SPECT study from $\mathrm{Pa}$ tient 3 does not support this hypothesis, since there was a clear and precocious activation of the damaged temporal lobe.

In this study, interictal epileptiform discharges among patients with EEG-lesion discordance were present in three different patterns: a) restricted to the non damaged hemisphere; b) bilateral but predominating on the non-damaged hemisphere; c) bilateral predominating on the damaged hemisphere. Different magnitudes of hemispheric injury and skull thickness could explain these lateralizing variations. These interictal EEG lateralizing variations were also present in the study of Sammaritano et al. ${ }^{2}$.

It is worth to emphasize the decisive role of the SPECT study on surgical indication of patient 3. Along with clinical lateralizing data, the method can be very useful for noninvasive lateralization of ictal onset in patients with large destructive lesions with discordant EEG features, and further studies will be helpful for better delineation of its usefulness at these circumstances.

In conclusion, our data show that compensatory skull thickening in patients with precocious destruc- tive brain insults are more frequent among patients with unilateral and large lesions. However, EEG lateralization discordance among these patients seems to be more related to EEG background abnormalities and the extent of cerebral damage than to skull changes.

\section{REFERENCES}

1. Dyke CG, Davidoff LM, Masson CB. Cerebral hemiatrophy with homolateral hypertrophy of the skull and sinuses. Surg Gynecol Obstet 1933; $57: 588-600$

2. Sammaritano $M$, de Lotbinière $A$, Andermann $F$, et al. False lateralization by surface EEG of seizure onset in patients with temporal lobe epilepsy and gross focal cerebral lesions. Ann Neurol 1987;21:361-369.

3. Zeiss J, Brinker RA. MR imaging of cerebral hemiatrophy. J Comput Assist Tomogr 1988;12:640-643.

4. Sener RN, Jinkins JR. MR of craniocerebral hemiatrophy. Clin Imaging 1992;16:93-97.

5. Teixeira RA, Li LM, Santos SL, et al. Early developmental destructive brain lesions and their relationship to epilepsy and hippocampal damage. Brain Dev 2003; "in press".

6. Kuzniecky RI, Jackson GD, Magnetic resonance in epilepsy. New York: Raven Press, 1995:142-144.

7. Barkovich AJ. Pediatric neuroimaging, 2nd ed. Philadelphia: LippincottRaven, 1996.

8. Engel JJ, Van Ness PC, Rassmussen TB, Ojemann LM. Outcome with respect to epileptic seizures. In Engel JJ (ed). Surgical treatment of the epilepsies, 2nd edition. New York: Raven Press, 1993: 609-621.

9. Alpers BJ, Dear RB. Hemiatrophy of the brain. J Nerv Ment Dis 1939;89:653-671.

10. Friede RL. Developmental neuropathology. New York: SpringerVerlag,1989.

11. Kataoka K, Okuno T, Mikawa H, Hojo H. Cranial computed tomographic and electroencephalographic abnormalities in children with post-hemiconvulsive hemiplegia. Eur Neurol 1988;28:279-284.

12. Ito M, Okuno T, Takao T, et al. Electroencephalographic and cranial computed tomographic findings in children with hemiplegic cerebral palsy. Eur Neurol 1981;20:312-318.

13. Dyken ML, White PT, Nelson G. Electroencephalographic lateralization in chronic infantile hemiplegia. Electroenceph Clin Neurophysiol 1964;17:693-695.

14. Palmini AL, Gloor P, Jones-Gotman M. Pure amnestic seizures in temporal lobe epilepsy. Brain 1992;115:749-769.

15. Gloor P, Salanova V, Olivier A, Quesney LF. The human dorsal hippocampal comissure. Brain 1993;116:1249-1273. 